\title{
A STUDY OF THE NATURE OF THE EMISSION CENTRES AND MECHANISMS OF RADIATIVE RECOMBINATION IN SEMI-INSULATING GaAs CRYSTALS
}

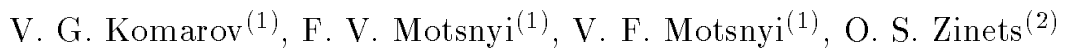 \\ (1) Institute of Physics of Semiconductors of the National Academy of Sciences of Ukraine, \\ 45 Nauky Pr., Kyiv, UA-252028, Ukraine \\ ${ }^{(2)}$ Institute for Nuclear Research of the National Academy of Sciences of Ukraine, \\ 47 Nauky Pr., Kyiv-22, UA-252022, Ukraine \\ (Received February 19, 1998)
}

\begin{abstract}
The low temperature photoluminescence spectra of semi-insulating GaAs crystals grown by Czochralski method at different technological conditions have been studied. One of the main background impurities in such materials is carbon. The traditional high temperature annealing of semiinsulating GaAs wafers significantly aggravates their structure perfection because near the surface the creation of conductive layers with the thickness of several microns takes place. The fine structure of the bands of 1.514 and $1.490 \mathrm{eV}$ has been registered. This structure caused by a) polariton emission from upper and low polariton branches; b) radiative recombination of free holes on shallow neutral donors $\left(D^{0}, h\right)$; c) radiative recombination of excitons bound to shallow neutral donors $\left(D^{0}\right.$, $X)$ and to shallow carbon acceptors $\left.\left(\mathrm{C}_{\mathrm{A}}^{0}, X\right) ; \mathrm{d}\right)$ excitons bound to the point structure defects $(d$, $X)$; e) electron transitions between the conduction band and shallow neutral carbon acceptor; f) the electron transitions between donor-acceptor pairs in which carbon and possibly zinc are acceptors in the ground $1 S_{3 / 2}$ state. The lux-intensity dependencies of the polariton emission from upper polariton branch and photoluminescence of $\left(D^{0}, h\right),\left(\mathrm{C}_{\mathrm{A}_{s}}^{0}, X\right),(d, X)$ complexes are in good agreement with the theory. It is shown that one of the best available semi-insulating GaAs materials is a new commercial AGCP-5V material which differs from others by considerable concentration of shallow donors and new acceptors alongside of the known shallow $\mathrm{C}_{\mathrm{AB}}^{0}$ acceptor centres.

Key words: photoluminescence, semi-insulating gallium arsenide, polariton, exciton, impurity complex, lux-intensity characteristics.
\end{abstract}

PACS number(s): 78.55.Cr

\section{INTRODUCTION}

Semi-insulating gallium arsenides are widely used in modern semiconductor device technology for manufacture of ultra high frequency (UHF) devices (FET with the Schottky barrier, avalanche-transit and Gunn diodes, VLSI , bistable devices etc.), which require high structural and topological perfection of crystals. To satisfy these requirements a detailed study of the interaction of impurities and intrinsic defects which are introduced in the crystal lattice at various technological operations (the crystal growth, the ion implantation, annealing, the surface treatment) is needed. Analysing the condition of creating different crystal lattice defects, one can optimise the technology of making devices, improve electrophysical properties and reliability of devices and increase the output of suitable devices [1].

The aim of the present work lies in investigating the nature of the centres and the mechanisms of the recombination radiation in semi-insulating gallium arsenide crystals, grown at different technological conditions.

\section{INFLUENCE OF GROWTH CONDITIONS AND TECHNOLOGICAL TREATMENT ON PHOTOLUMINESCENCE PROPERTIES OF GaAs}

Different (laboratory: AR-19, AR-40, and commercial: AGP-2, AGP-3, AGP-4, AGP-5) types of semi-insulating gallium arsenide crystals, grown by the Czochralski method, were investigated. Wafers with thickness of $300-500 \mu \mathrm{m}$ had [100] orientation and were etching with the polishing solution of $\mathrm{H}_{2} \mathrm{SO}_{4}: \mathrm{H}_{2} \mathrm{O}_{2}: \mathrm{H}_{2} \mathrm{O}=1: 1: 3$.

Photoluminescence (PL) spectra were registered by the monochromator MDR-4, having middle resolution, from the side of the incidence light beam in the energy range of $0.50-1.52 \mathrm{eV}$ and for the temperature interval of 4.2-300 K. Typical characteristics of measured PL spectra of many initial and annealed semi-insulating GaAs substrates registered at the same condition are shown in table 1 .

One can see the following peculiarities:

- spectra of substrates from AR-19, AR-40, AGP-2, 
AGP-3 materials are simple and as a rule consist of the single band at $1.485 \mathrm{eV}$;

- spectra of substrates from AGP-4, AGP-5 materials are more complicated and consist of 3 to 5 bands of different intensities;

- the most short-wavelength band $1.512 \mathrm{eV}$ is a sharp peak only in the AGP-4, AGP-5 materials;

- in the spectra of annealed samples the broadening of the band $1.512 \mathrm{eV}$ and increase of the intensity of the band $1.485 \mathrm{eV}$ are observed. Besides an additional band $1.35 \mathrm{eV}$ can arise.

It is necessary to point out that the number of bands and their intensities in PL spectra registered from different parts of samples at the spectrum for initial and annealed wafers were unchanged. This indicates on the homogeneity of investigated samples which have sizes comparable with the sizes of spots of the exciting laser beam $(300 \mu \mathrm{m})$. Intensity of the recombination radiation of substrates decreases with the increase of temperature, new bands or other peculiarities in spectra were not observed.

Let us analyse the above mentioned experimental data. The shortest wave band $1.512 \mathrm{eV}$ corresponds to the edge PL of GaAs. It has large half width ( $5 \mathrm{meV})$ in the energy range of $1.510-1.515 \mathrm{eV}$. In this range the radiation is due to polaritons, exciton-impurity complexes (EIC) and quantum transitions with the participation of free charge carriers and impurity centres. Therefore the interpretation of this PL band in spectra registered with a middle resolution have some difficulties.

\begin{tabular}{|c|c|c|c|c|}
\hline \multirow{2}{*}{$\begin{array}{l}\text { Type of } \\
\text { material }\end{array}$} & \multicolumn{2}{|r|}{ Initial } & \multicolumn{2}{|c|}{ After annealing } \\
\hline & $\begin{array}{c}\text { Position of } \\
\text { PL band } \\
\text { maximum, } \\
\text { eV }\end{array}$ & \begin{tabular}{|c|} 
Short \\
characteristics of \\
the bands
\end{tabular} & $\begin{array}{c}\text { Position of } \\
\text { PL band } \\
\text { maximum, } \\
\text { eV }\end{array}$ & $\begin{array}{c}\text { Short } \\
\text { characteristics of } \\
\text { the bands }\end{array}$ \\
\hline \multirow{3}{*}{$\mathrm{AR}-19$} & 1.512 & weak broadened & 1.512 & weak broadened \\
\hline & 1.485 & middle intensity & 1.485 & middle intensity \\
\hline & - & - & 1.35 & weak wide band \\
\hline \multirow[t]{2}{*}{$\mathrm{AR}-40$} & 1.485 & middle intensity & 1.485 & high intensity \\
\hline & - & - & 1.35 & weak wide band \\
\hline AGP-2 & 1.485 & middle intensity & 1.485 & intense band \\
\hline $\mathrm{AGP}-3$ & 1.485 & middle intensity & 1.485 & intense band \\
\hline \multirow{4}{*}{$\mathrm{AGP}-4$} & 1.512 & weak sharp peak & 1.512 & weak broadened \\
\hline & 1.485 & intense band & 1.485 & $\begin{array}{c}\text { band the same or } \\
\text { larger intensity }\end{array}$ \\
\hline & 1.450 & weak sharp peak & 1.450 & $\begin{array}{c}\text { weak broadened } \\
\text { band }\end{array}$ \\
\hline & - & - & 1.35 & weak wide band \\
\hline \multirow{5}{*}{$\mathrm{AGP}-5$} & 1.512 & $\begin{array}{l}\text { sharp peak of } \\
\text { middle intensity }\end{array}$ & 1.512 & broadened band \\
\hline & 1.485 & intense band & 1.485 & $\begin{array}{l}\text { band the same or } \\
\text { larger intensity }\end{array}$ \\
\hline & 1.450 & middle intensity & 1.450 & middle intensity \\
\hline & 1.35 & weak wide band & 1.35 & weak wide band \\
\hline & 0.650 & weak wide band & 0.650 & weak wide band \\
\hline
\end{tabular}

Table 1. Peculiarities of PL spectra of initial and thermally annealed semi-insulating GaAs substrates of different types. $T=4.2 \mathrm{~K} . \lambda_{\text {excit }}=6328 \AA$

On the other hand the edge PL reflects the crystals quality [2], because its intensity is proportional to the extrinsic charge carrier concentration, which is reverse proportional to the deep centre concentration. Analysing the band $1.512 \mathrm{eV}$ in various samples one can made a conclusion concerning the quality of samples as well as concerning their structure changes under different technological treatments. Hence, broadening and absence of the $1.512 \mathrm{eV}$ band in PL spectra of the initial AR-19, AR-40, AGP-2, AGP-3 materials, and its arising as a sharp peak in PL spectra of initial AGP-4, AGP-5 materials directly testifies to a high structure quality of substrates AGP-4, AGP-5. These substrates have a smaller content of the crystal lattice defects which act as nonradiative recombination centres.

The traditional high temperature annealing leads to a decrease of the structure quality of substrates. It is proved by broadening and decreasing of intensity of the band $1.512 \mathrm{eV}$. In some cases we have an increase of the intensity of the band $1.485 \mathrm{eV}$, absence of the band 
$1.450 \mathrm{eV}$ and creation of additional emission centres (the band $1.35 \mathrm{eV}$ ). Therefore it is necessary to consider the nature of other bands.

The band $1.485 \mathrm{eV}$ is connected to carbon impurity in GaAs [3-6]. Replacing $\mathrm{Ga}$ and As in sites of the crystal lattice with carbon atoms the shallow donor-acceptor $(D-A)$ pairs are created with the binding energy of the $\mathrm{C}$ acceptor $E_{A}=26.5 \mathrm{meV}$. In the framework of such concepts one can explain the temperature quenching of $\mathrm{PL}$ of the band $1.485 \mathrm{eV}$ and increasing of the quantum yield of the recombination radiation of this band after the annealing. An additional evidence of the presence of carbon in these samples is its observation by the emission analysis method (carbon concentration $10^{16} \mathrm{~cm}^{-3}$ ).

The distance between the bands $1.450 \mathrm{eV}$ and $1.485 \mathrm{eV}$ corresponds to the LO-phonon energy $\left(E_{\mathrm{ph}}=36 \mathrm{meV}\right)$. This allows to interpret the band $1.450 \mathrm{eV}$ as the LOphonon satellite of the band $1.4845 \mathrm{eV}$ that agrees with the absence of the band $1.450 \mathrm{eV}$ in low quality crystals.

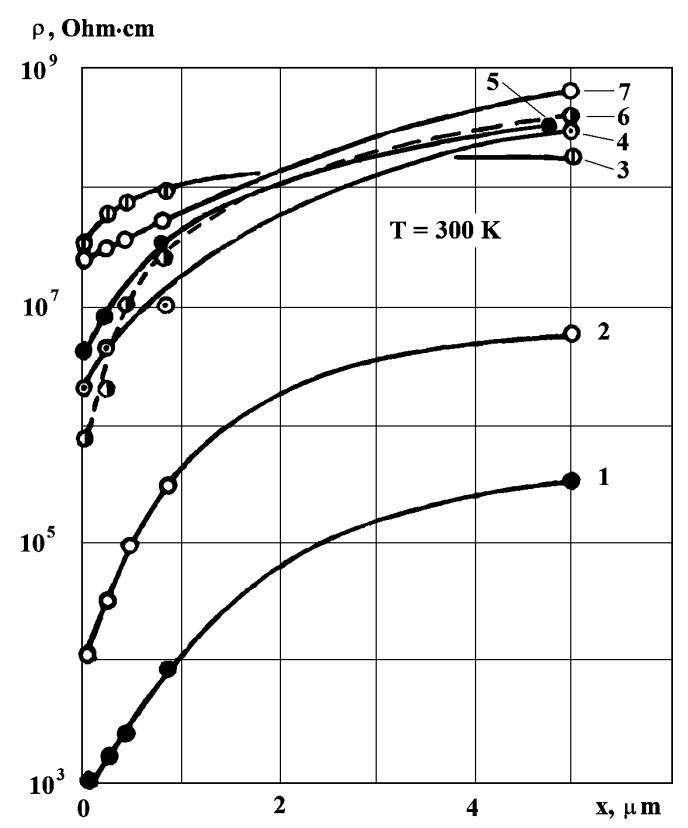

Fig. 1. The conductivity of thermally annealed semiinsulating GaAs substrates under layer by layer etching. Materials: 1-AR-19, 2-AR-40, 3-AGCP-4, 4,5-AGCP-5, 6-AGP-3, 7-AGP-5; $T=300 \mathrm{~K}$.

The band $1.35 \mathrm{eV}$ is connected to Cu impurity and it is due to the radiative capture of electrons from the conductivity band or shallow donor centres $\left(E_{D}=5 \mathrm{meV}\right)$ by the deep Cu neutral acceptor $\left(E_{A}=0.15 \mathrm{eV}\right)$. Chemical structure of the last centre was studied by the piezospectroscopic method in $[7,8]$, which shows that this complex centre has the $C_{2 V}$ symmetry. This complex contains a $\mathrm{Cu}$ atom in the site of the Ga atom and the nearest four As atoms are displaced from the crystal lattice sites to new equilibrium positions under the action of Jan-Taller effect which arises as a result of interaction of the hole on the centre with the oscillation of atoms of the complex. Broadening of the $1.35 \mathrm{eV}$ band and the absence of its phonon satellite indicates that under annealing the structure perfection of GaAs crystals are aggravating. The band $1.35 \mathrm{eV}$ is present mainly in PL of annealed samples. Therefore it is necessary to control carefully all possible sources of $\mathrm{Cu}$ contamination.

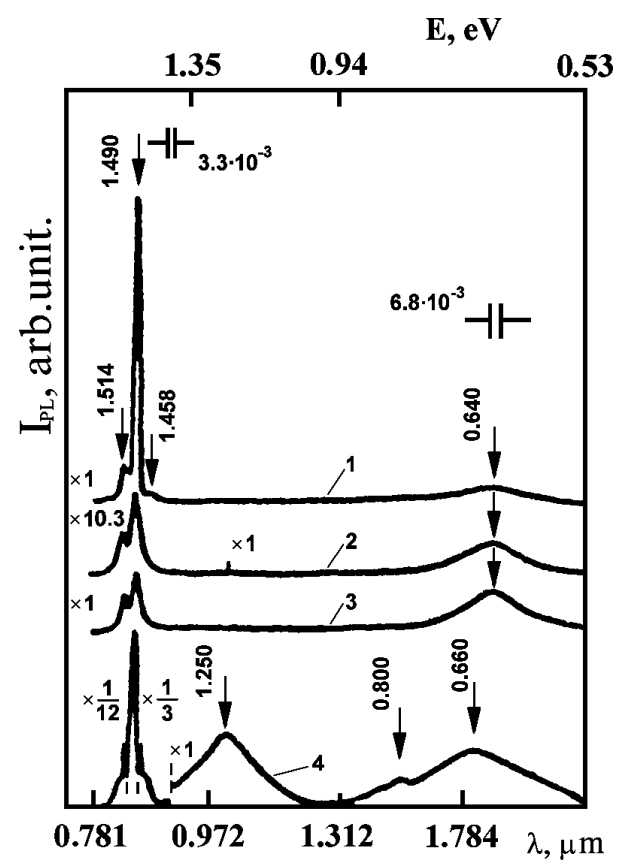

Fig. 2. PL spectra of semi-insulating GaAs crystals: 1-AGCP-3, 2-AGCP-4, 3-AGCP-5, 4-specially doped by $\mathrm{Cr} ; T=4.2 \mathrm{~K} ; \lambda_{\text {excit }}=6328 \AA$.

Hence, the traditional high temperature annealing of semi-insulating GaAs substrates significantly aggravates their structure perfection. It is connected with the dissociation of $\mathrm{GaAs}$, the depletion of surface layer by As atoms, the diffusion of carbon, copper and other elements both from the external environment and, possibly, from the bulk into the near surface region. This conclusion is confirmed by the direct measurements of the resistivity of semi-insulating substrates under layer-by-layer etching. Results of the measurements are shown in fig. 1. One can see that near the surface the GaAs lattice is broken most significantly because of the creation of the conductive surface layers with the thickness of several microns.

In the PL spectra of the majority of the investigated samples the band $0.8 \mathrm{eV}$ which corresponds to $\mathrm{Cr}$ [4] is absent, though the majority of semi-insulating samples are obtained by $\mathrm{Cr}$ compensation. This testifies to low $\mathrm{Cr}$ concentration in the samples. To determine the charge state and the concentration of $\mathrm{Cr}$ we investigate the electron spin resonance (ESR) spectra of this samples at $4.2 \mathrm{~K}$ with high-sensitive ESR-spectrometer Varian$\mathrm{E}-12$. However the presence of $\mathrm{Cr}$ was not found even in massive specially selected samples in which the band 
$0.8 \mathrm{eV}$ in $\mathrm{PL}$ spectrum was observed clearly and had high intensity. An estimation of $\mathrm{Cr}$ concentration, taking into account the data of the works $[1,8]$, gives the value smaller then $10^{15}-10^{16} \mathrm{~cm}^{-3}$.

So the experimental data testifies to low structure perfection of semi-insulating GaAs materials AR-19, AR40, AGP-2, AGP-3, AGP-4 and AGP-5.

\section{NONDESTRUCTIVE QUALITY CONTROL OF GaAs SUBSTRATES}

Let us consider the results of PL studies of others commercial GaAs substrates: AGCP-3, AGCP-4, AGCP-5. Peculiarities of manufacturing of these materials grown by Czochralski method are presented in table 2 .

\begin{tabular}{|c|c|c|}
\hline $\begin{array}{c}\text { Type of } \\
\text { materials }\end{array}$ & Doping impurity & $\begin{array}{c}\text { Content of } \\
\text { chromium, } \%\end{array}$ \\
\hline AGCP-3 & Cr, O, In & $\leq 1.7 \cdot 10^{-5}$ \\
\hline AGCP-4 & In & - \\
\hline AGCP-5 & specially undoped & - \\
\hline
\end{tabular}

Table 2. The impurity content of AGCP-3, AGCP-4, AGCP5 materials.

The substrates with mirror surfaces were obtained by chemical etching in the standard solution $\left(\mathrm{H}_{2} \mathrm{SO}_{4}: \mathrm{H}_{2} \mathrm{O}_{2}: \mathrm{H}_{2} \mathrm{O}=1: 1: 3\right)$. The thickness of the wafers were $300-500 \mu \mathrm{m}$. The samples were oriented in [100] direction.

Typical PL spectra of these samples at $4.2 \mathrm{~K}$ are shown in fig. 2. It is seen that spectra are in the main similar and contain of three bands $1.514,1.490$ and $0.64 \mathrm{eV}$. However these spectra essentially differ from PL spectra of previous samples:

- the edge PL band $1.514 \mathrm{eV}$ is a sharp peek;

- the intensity of the band $1.490 \mathrm{eV}$ is lower and decreases from AGCP-3 material to AGCP-5 material;

- the band $1.458 \mathrm{eV}$ in PL spectra of AGCP-3 material is weak and disappears in PL spectra of AGCP-4 and AGCP-5 materials;

- the energy maximum of the lowest energy band is shifted by $20 \mathrm{meV}$ to low energy region and equals $0.64 \mathrm{eV}$.

At the same time the spectra (number of bands and their intensities from different regions of all samples) were unchanged, that indicates on homogeneity of samples with the size of the order of the laser spot diameter $(\approx 300 \mu \mathrm{m})$.

Earlier registered bands were observed by us at studies of other samples. Their nature was discussed above: bands $1.490,0.80$, and $0.64 \mathrm{eV}$ are due to $\mathrm{C}$. Cr or O impurities respectively, and the band $1.458 \mathrm{eV}$ is the $\mathrm{LO}-$ phonon satellite of the band $1.485 \mathrm{eV}$.
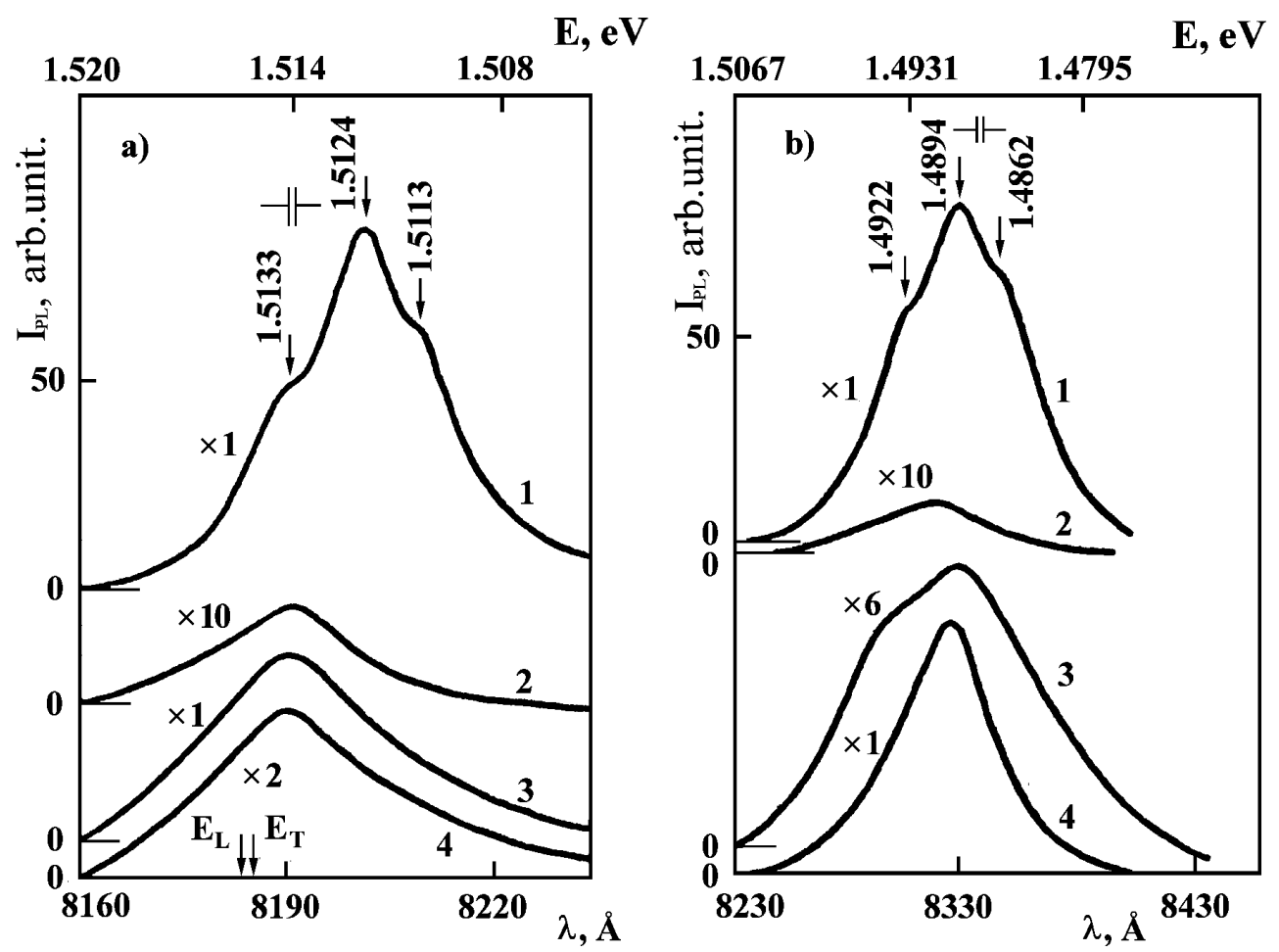

Fig. 3. PL spectra of semi-insulating GaAs crystals: 1-AGCP-3, 2-AGCP-4, 3-AGCP-5, 4-specially doped by Cr. $E_{L}, E_{T}$ — energies of longitudinal and transverse excitons a $-1.514 \mathrm{eV}, \mathrm{b}-1.490 \mathrm{eV}$ bands; $T=4.2 \mathrm{~K} ; \lambda_{\text {excit }}=6328 \AA$. 
Let us estimate the quality of the AGCP-3, AGCP-4 and AGCP-5 materials. Within the framework of traditional analysis when only the edge PL is studied, the structure perfection of the AGCP-3, AGCP-5 materials is approximately the same and is better than that of the AGCP-4 material and traditional materials with $\mathrm{Cr}$ impurity, though as our investigations show, their perfection is not exactly the same, because of different content of oxygen and carbon. Carbon creates acceptor centres $\mathrm{C}_{\text {As }}$, and scattering by these centres leads to decreasing the carrier mobility [8], influence of oxygen was not observed. So, due to a lower content of $\mathrm{C}$, the advantage of the AGCP-5 material is obvious.
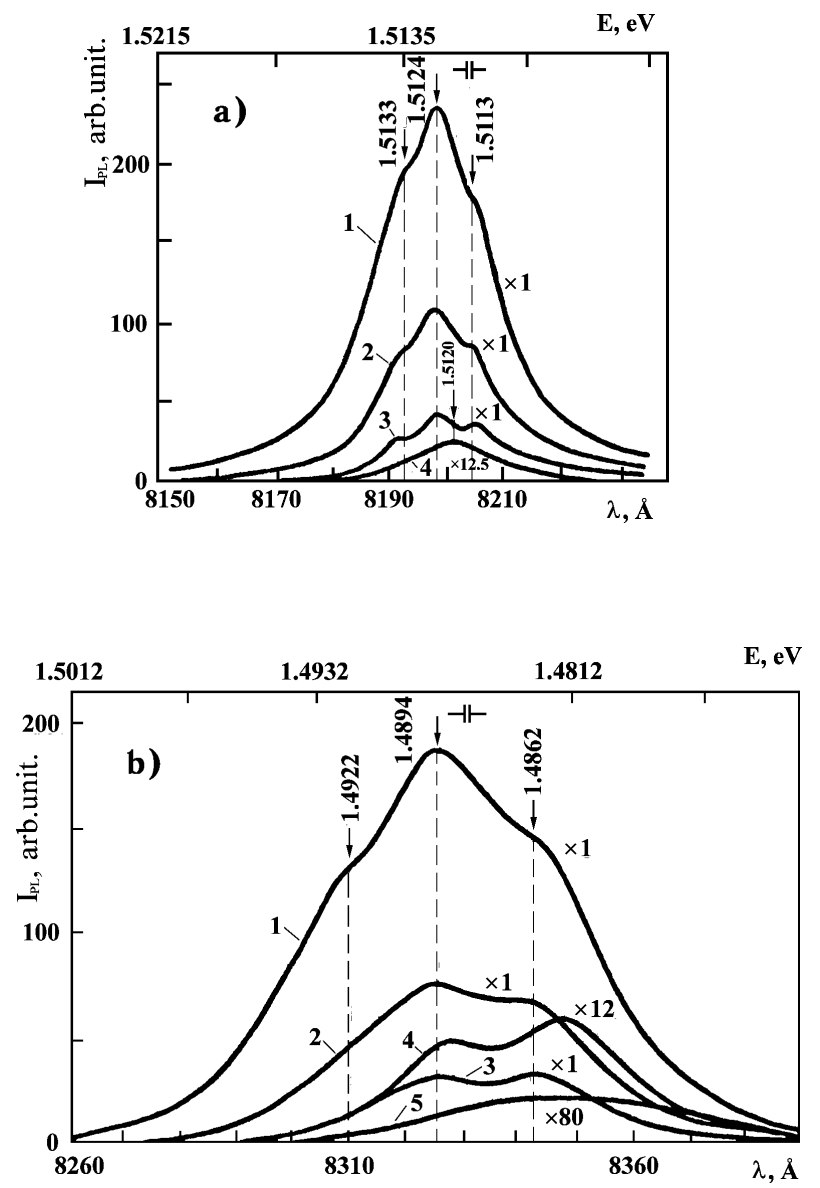

Fig. 4. PL spectra of AGCP-3 under different excitation intensities. a - band $1.514 \mathrm{eV}: 1-I_{0}, 2-0.38 \cdot I_{0}, 3-$ $0.17 \cdot I_{0}, 4-0.07 \cdot I_{0} ; \mathrm{b}-$ band $1.490 \mathrm{eV}: \mathrm{I}-I_{0}, 2-$ $0.29 \cdot I_{0}, 3-0.13 \cdot I_{0}, 4-0.07 \cdot I_{0}, 5-0.04 \cdot I_{0} ; T=4.2 \mathrm{~K}$; $\lambda_{\text {excit }}=6328 \AA$.

A low quantum yield of PL of the band $1.514 \mathrm{eV}$ (as well as in other bands in PL spectra of AGCP-4 material) can not be explained only by the influence of carbon or oxygen. However, the situation is clearing, when non-radiative recombination of centres are including. In fact, the influence of such centres on the intensity of the band $1.490 \mathrm{eV}$ at $4.2 \mathrm{~K}$ significantly dominates over the influence of the deep donors EL2 [9] in semiinsulating GaAs crystals with the indium concentration of $\approx 2 \div 5 \cdot 10^{20} \mathrm{~cm}^{-3}$.

Hence, the semi-insulating AGCP-5 material has higher quality in comparison with both laboratory (AR) and commercial (AGP, AGCP-3, AGCP-4) materials.

\section{INVESTIGATION OF GaAs PHOTOLUMINESCENCE BY HIGH RESOLUTION SPECTROSCOPY}

Among the bands which are observed in PL spectra of AGCP and traditional GaAs(Cr) materials the $1.514,1.490 \mathrm{eV}$ bands change the most strongly reflecting the quality of samples. It is known that these bands in PL spectra of epitaxial GaAs layers have a fine structure which is due to free excitons, EIC, $D-A$ pairs and bandacceptor $\left(E_{c}-A\right)$ transitions [10]. So, to obtain an additional information on GaAs semi-insulating materials we used the high resolution spectrometer DFS-24 with the resolution better than $0.1 \mathrm{meV}$. Typical PL spectra of AGCP-3, AGCP-4, AGCP-5 and $\mathrm{GaAs}(\mathrm{Cr})$ materials at $4.2 \mathrm{~K}$ are shown in fig. 3 .

We revealed peculiarities which were not observed earlier:

- the fine structure of bands 1.514 and $1.490 \mathrm{eV}$ is observed for the AGCP-3 material. Each of these bands consists of three lines with the maxima at $1.5133,1.5124,1.5113 \mathrm{eV}$ and $1.4922,1.4894$, $1.4862 \mathrm{eV}$ respectively. They have approximately the same distribution of intensities between the lines: the middle line is the most intense, the short wave length line is weaker than the long wave line;

- the maximum of the edge PL band for AGCP4, AGCP-5, GaAs(Cr) materials coincides with the position of the short wave length component $1.5133 \mathrm{eV}$ of the band $1.514 \mathrm{eV}$ for AGCP-3 material;

- the fine structure of the band $1.490 \mathrm{eV}$ in PL spectra for AGCP-4 and GaAs(Cr) materials was not observed, while in the spectra of AGCP-5 material we have the doublet $(1.4922,1.4894 \mathrm{eV})$. The short wave length component of this doublet is weaker than the long wave length one.

To clear the nature of the fine structure of the bands 1.512 and $1.490 \mathrm{eV}$ in PL spectra of semi-insulating GaAs materials we consider the influence of temperature and the laser beam intensity on these bands for AGCP3 material, because PL spectra of this material have a number of peculiarities, which are partially present in the spectra of other materials. We shall restrict ourselves by a case of low level of pumping when the exciton interaction can be neglected $\left(n_{\mathrm{ex}} r_{\mathrm{ex}}^{3}<1, n_{\mathrm{ex}}\right.$ is the exciton concentration, $r_{e x}$ is the exciton radius). 
Fig. 4 shows PL spectra of semi-insulating GaAs materials at different excitation intensities. One can see that increasing $I_{\text {excit }}$ leads not only to an increase in PL intensity but to the transformation of the long wave length components of the bands 1.514 and $1.490 \mathrm{eV}$ to the shortwave ones. The dependence of $I_{\mathrm{PL}}$ on $I_{\text {excit }}$ is satisfactorily described by the formula $I_{\mathrm{PL}}=\left(I_{\text {excit }}\right)^{\alpha_{i}}$, where $\alpha_{i}$ corresponds to different components of the fine structure of the bands 1.514 and $1.490 \mathrm{eV}$ (the values of $\alpha_{i}$ obtained from the slopes of the corresponding lines are shown in the table 3 ).

\begin{tabular}{|c|c|c|c|}
\hline Band, eV & $\begin{array}{l}\text { Components } \\
\text { of the fine } \\
\text { structure, eV }\end{array}$ & $\alpha_{I}$ & $\begin{array}{c}\text { Excitation light } \\
\text { intensities, } \\
I_{\text {excit }} / I_{0}\end{array}$ \\
\hline \multirow[t]{6}{*}{1.514} & \multirow[t]{2}{*}{1.5133} & 1.2 & $0.71-1.00$ \\
\hline & & 2.4 & $0.09-0.17$ \\
\hline & \multirow[t]{2}{*}{1.5124} & 1.1 & $0.20-1.00$ \\
\hline & & 2.3 & $0.09-0.20$ \\
\hline & \multirow[t]{2}{*}{1.5113} & 1.1 & $0.20-1.00$ \\
\hline & & 2.3 & $0.09-0.20$ \\
\hline \multirow[t]{7}{*}{1.490} & 1.4922 & $\overline{0.65}$ & $0.40-1.00$ \\
\hline & \multirow[t]{3}{*}{1.4894} & 0.65 & $0.40-1.00$ \\
\hline & & 1.1 & $0.13-0.40$ \\
\hline & & 3.1 & $0.05-0.13$ \\
\hline & \multirow[t]{3}{*}{1.4862} & 0.65 & $0.40-1.00$ \\
\hline & & 1.0 & $0.13-0.40$ \\
\hline & & 2.9 & $0.05-0.013$ \\
\hline
\end{tabular}

Table 3. Values of parameters $\alpha_{I}$ for components of the bands 1.514 and $1.490 \mathrm{eV}$ in PL spectrum of AGCP-3 material. $T=4.2 \mathrm{~K} . \lambda_{\text {excit }}=6328 \AA$.

The maximum positions of different lines of both bands are changed with the increasing of $I_{\text {excit }}$. It should be noticed that the maxima of $1.4894,1.4862 \mathrm{eV}$ linearly shift to the violet part of the spectrum by 1.0 and 1.7 meV respectively at $I_{\text {excit }}>0.11 I_{0}$, while the maxima $1.5133,1.5124,1.5113$ and $1.4922 \mathrm{eV}$ are unchanged.

For a clearer selection of the fine structure of the bands 1.514 and $1.490 \mathrm{eV}$ the temperature studies were carried out for fixed intensity of the exciting laser light. As seen from fig. 5-6 both bands are rather sensitive to temperature. The longwave components 1.5113 and $1.4862 \mathrm{eV}$ are damped at the temperature lager than $4.2 \mathrm{~K}$ by several degree. This indicates on small value of the binding energy of centres which correspond to these lines. Decreasing of PL intensities of the remainder components $1.5133,1.5124,1.4922,1.4894 \mathrm{eV}$ is the most essential in the range of $10-25 \mathrm{~K}$. In this temperature range exponential damping of the lines is observed with the thermal activation energy of $5.0,2.7,2.5,1.5 \mathrm{meV}$ (these energies were determined by the standard method) respectively. The energy position of the components 1.5133 , $1.5124,1.4922 \mathrm{eV}$ are not changed while the component $1.4894 \mathrm{eV}$ at $T>20 \mathrm{~K}$ manifests a trend to a shortwave shift.

After temperature damping of the fine structure components the band $1.514 \mathrm{eV}$ is not as a structural band (fig. 5b, fig. 7), with the subsequent increasing temperature, their intensity exponential decreasing (the thermal activation energy 30 and $52 \mathrm{meV}$ in the ranges $40-60$ and $60-80 \mathrm{~K}$ respectively, and the maximum shift to the longwave region nonlinearly $\left(d E / d T \approx-4 \cdot 10^{-4}\right.$, $d E / d T \approx-6 \cdot 10^{-4} \mathrm{eV} / \mathrm{K}$ in the ranges $40-60$ and $60-80 \mathrm{~K}$ respectively). The latter fact is in satisfactory agreement with the temperature behaviour of the gap $\left(d E_{G} / d T \approx-5 \cdot 10^{-4} \mathrm{eV} / \mathrm{K}\right)[11]$
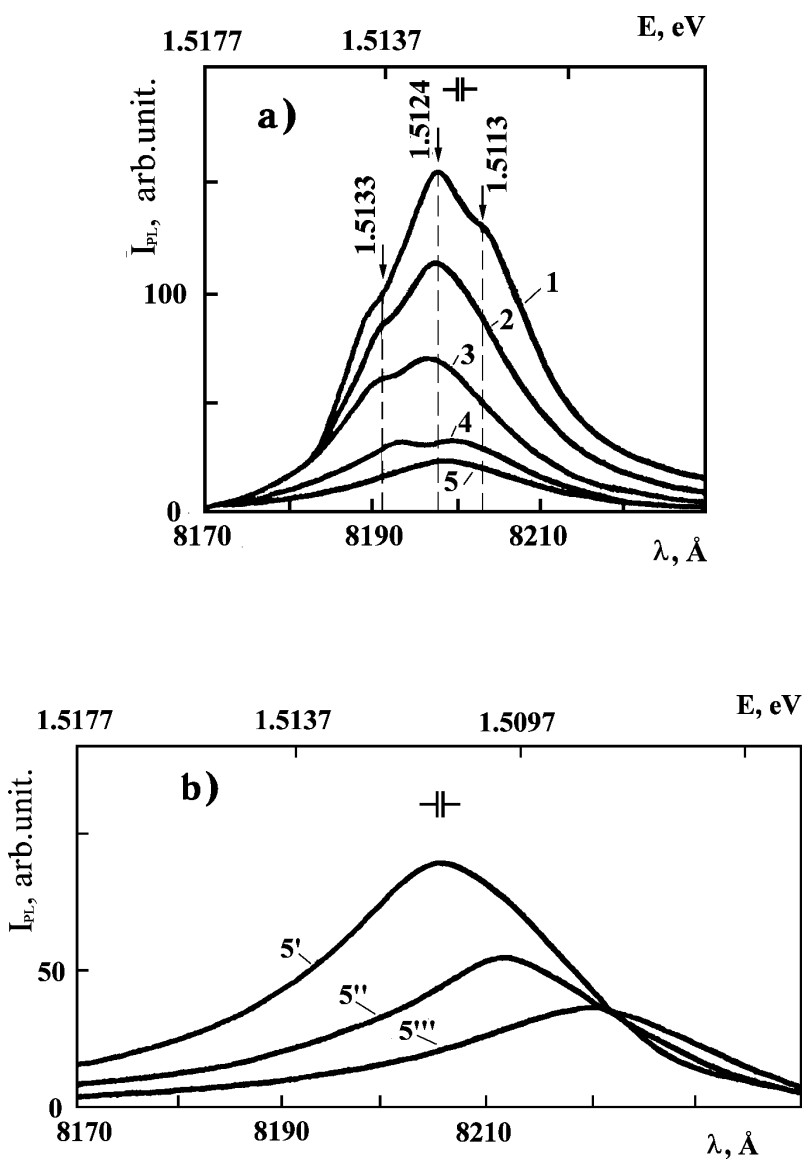

Fig. 5. Temperature changes of the band $1.514 \mathrm{eV}$ in $\mathrm{PL}$ spectra of AGCP-3 material a-structural band. T, K: 1 4.2, $2-9.5,3-14,4-22$; b - structureless band. $T$, K: $5-30,5^{\prime}-45,5^{\prime \prime}-54,5^{\prime \prime \prime}-63 ; \lambda_{\text {excit }}=6328 \AA$.

The surfaces of all the investigated samples were treated similarly, therefore the differences in PL spectra of various samples are not connected with the surface recombination centres. These differences can not be connected to isovalence to $\mathrm{Ga}$ impurity In, either because spectra of the AGCP-3 and AGCP-4 materials containing it, significantly differ.

In the range of the longitudinal-transverse splitting of excitons in PL spectra of the considered semi-insulating GaAs crystals the PL lines are absent. These lines are due to transitions from upper and low polariton branches $[12,13]$ and their presence would be a direct indication on high structure perfection of samples. So the absence of 
the polariton PL even in the best $\mathrm{AGCP}-5$ and $\mathrm{AGCP}-$ 3 materials indicates to a large content of different lattice defects in the investigated samples. An additional argument in support of such a conclusion is a differing behaviour of the fine structure of the bands 1.514 and $1.490 \mathrm{eV}$ in the PL spectra of different samples.

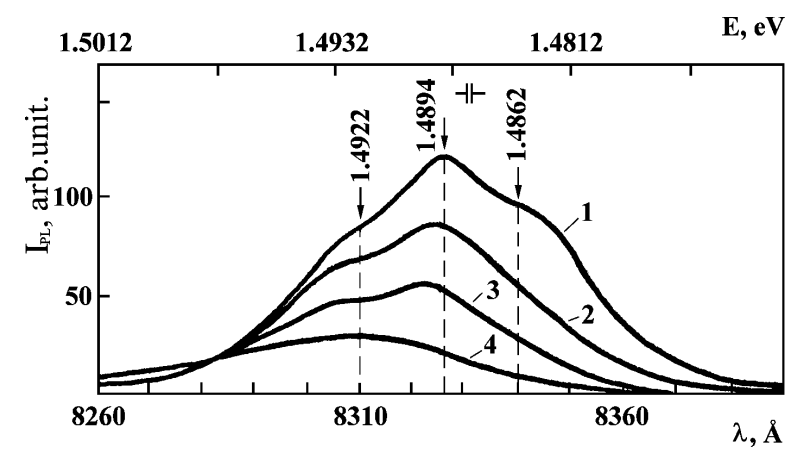

Fig. 6. Temperature changes of the band $1.490 \mathrm{eV}$ in $\mathrm{PL}$ spectra of AGCP-3 material. $T, \mathrm{~K}: 1-4.2,2-11,3-22$, $4-33 ; \lambda_{\text {excit }}=6328 \AA$.

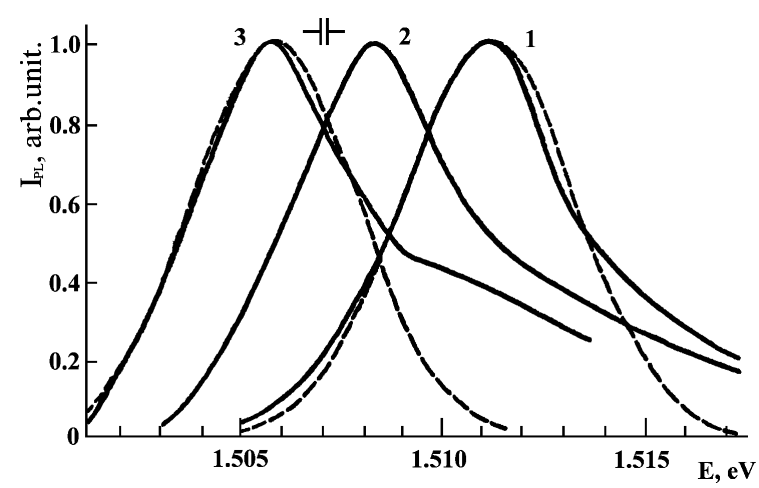

Fig. 7. Temperature changes of the structureless band in PL spectra of AGCP-3 material: solid curves-experiment, dashed curves - the Gauss curves. T, K: $1-45,2-65,3$ $-76 ; \lambda_{\text {excit }}=6328 \AA$.

A detailed analysis of experimental data, obtained under high resolution at different temperatures and intensities of the laser light with taking into account theoretical calculation of Bogardus and Bubb [14], allows to determine the nature of the fine structure components. This fine structure is caused by:

- the recombination radiation of free holes on shallow neutral donors with the thermal ionisation energy $5 \mathrm{meV}\left(D^{0}, h\right)(1.5133 \mathrm{eV})$;

- the recombination of excitons bound to shallow carbon acceptors $\left(\mathrm{C}_{\mathrm{As}}^{0}, X\right)(1.5124 \mathrm{eV})$ and point structure defects $(d, X)(1.5113 \mathrm{eV})$;
- the electron transitions between the conductivity band and the shallow neutral carbon acceptor $\left(E_{\mathrm{C}^{-}}\right.$ $\left.\mathrm{C}_{\mathrm{As}}^{0}\right)(1.4922 \mathrm{eV})$;

- the electron transitions between D-A pairs, in which carbon $\left(\mathrm{C}_{A s}^{0}\right)(1.4894 \mathrm{eV})$ and possibly zinc $\left(\mathrm{Zn}_{A s}^{0}\right)(1.4862 \mathrm{eV})$ are acceptors in the ground $1 S_{3 / 2}$ state with the thermal ionisation energies $\mathrm{C}_{A s}^{0} 26.5$ and $30.2 \mathrm{meV}$ respectively.

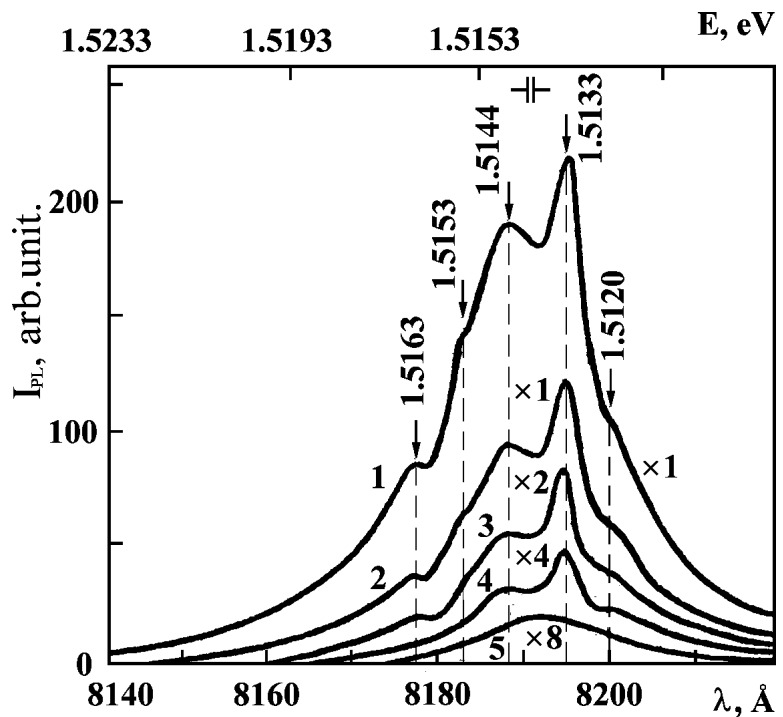

Fig. 8. PL spectra of AGCP-5V material under different excitation intensities: $-\mathrm{I}_{0}, 2-0.68 \cdot I_{0}, 3-0.21 \cdot I_{0}, 4-$ $0.12 \cdot I_{0}, 5-0.08 \cdot I_{0} . T=4.2 \mathrm{~K} . \lambda_{\text {excit }}=6328 \AA$.

A new acceptor level $E_{V}+0.052 \mathrm{eV}$ which is registered in GaAs crystals with In impurity may be caused by defects connected with this impurity.

For the $\left(D^{0}, h\right),\left(\mathrm{C}_{\mathrm{As}}^{0}, X\right),(d, X)$ complexes in semiinsulating GaAs crystals we have for PL intensity

$$
I_{P L} \sim\left(I_{\text {excit }}\right)^{\alpha_{i}}
$$

where $\alpha_{i}=2.0$ and 1.1 at low and high pumping levels respectively. This fact agrees satisfactory with theoretical results obtained in the work [15] for the dependence of the exciton PL intensity on the exciting light intensity $I_{\text {excit }}$ at of strongly absorbed light $(k L \gg 1, k$ is the absorption coefficient, $L$ is the diffusion length of the generated electrons and holes), while at low intensities $I_{\mathrm{PL}} \approx I_{\text {excit }}^{2}$ and at high intensities $\left.I_{\mathrm{PL}} \approx I_{\text {excit }}\right)$

In [15] the problem was reduced to the solution of the diffusion equations for electrons, holes and excitons

$$
D \frac{d^{2} n}{d x^{2}}-\frac{n}{\tau}-\alpha n^{2}+\beta n_{e x}=-G(x)
$$




$$
D_{e x} \frac{d^{2} n_{e x}}{d x^{2}}-\left(\frac{1}{\tau_{e x}}+\beta\right) n_{e x}+\alpha n^{2}=0
$$

where $n$ is the concentration of electrons and holes which are supposed to be equal, $D$ is the diffusion coefficient, $\tau$ is the lifetimes of electrons and holes; $n_{e x}, D_{e x}, \tau_{e x}$ are the concentration, the diffusion length and the lifetime of excitons, $\alpha$ is the probability of binding of $\mathrm{e}-\mathrm{h}$ pairs into exciton, $\beta$ is the probability of thermal dissociation of exciton, $G(x)$ is the generation rate of electrons and holes, $x$ is the coordinate.

Neglecting the surface exciton recombination the following formula was obtained for the total number of excitons in a sample:

$$
N_{\text {ex }}=\alpha \tau_{\text {ex }} \int_{0}^{\infty} n^{2}(x) d x
$$

The boundary condition was taken in the form

$$
\left.D\left(\frac{d n}{d x}+s n\right)\right|_{x=0}=I_{\text {excit }}=\int_{0}^{\infty} G(x) d x
$$

where $s$ is the velocity of surface non-radiative recombination of electrons and holes The condition of low intensity of excitation is

$$
I_{\text {exit }} \ll \frac{3 D}{2 \alpha \tau L}(1+s L)
$$

and for the intensity of PL we have

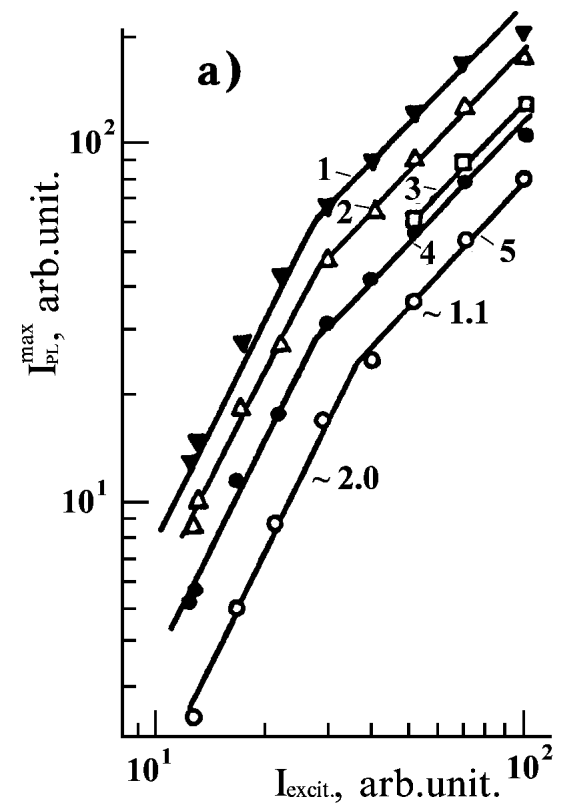

$$
I_{\mathrm{PL}} \sim N_{\mathrm{ex}} \sim\left(I_{\text {excit }}\right)^{2}
$$

For high excitation levels when

$$
I_{\text {exit }} \gg \frac{3 D}{2 \alpha \tau L}(1+s L)^{3}
$$

we have

$$
I_{\mathrm{PL}}=I_{\text {excit }}
$$

In the intermediate case when

$$
\frac{3 D}{2 \alpha \tau L}(1+s L) \ll I_{\text {excit }} \ll \frac{3 s^{3} D^{2}}{\alpha}
$$

one can obtain from eq. 9:

$$
I_{\mathrm{PL}} \sim\left(I_{\text {exit }}\right)^{\frac{3}{2}}
$$

So the deviation of the lux-intensity characteristics of the recombination radiation of EIC from a linear dependence at high pumping levels can be connected with the distribution of the excitation energy between recombination channels; the recombination radiation of carriers at the surface of the sample, their diffusion into the bulk and so on. The appearance of a superliner region for $D-$ A pairs in semi-insulating GaAs crystals at low levels of excitation is due to different mechanisms of radiative recombination which was also registered in other semiconductors $[2,16]$.

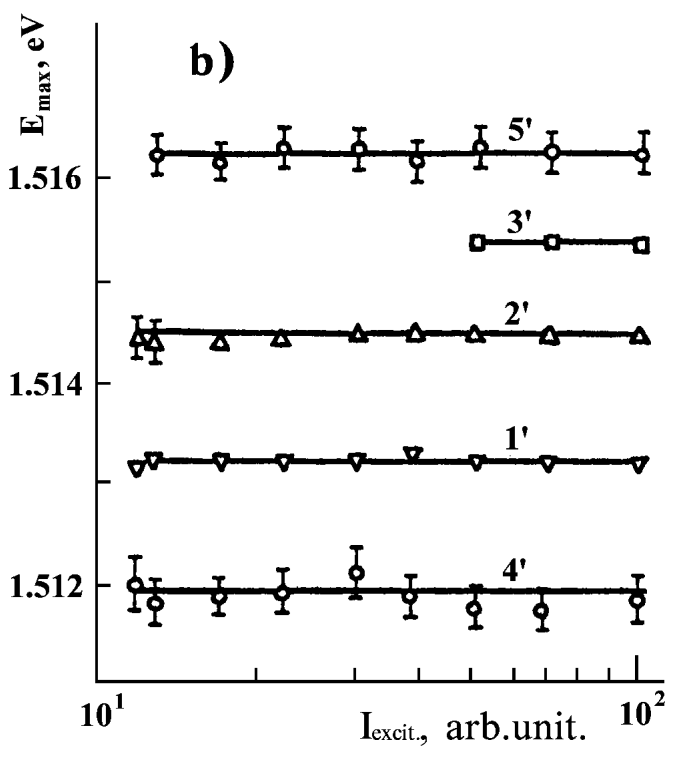

Fig. 9. Intensities in maxima (a) and energies (b) of PL lines of AGCP-5V material under different excitation intensities. $h \cdot \nu_{\max }: 1,1^{\prime}-1.5133 ; 2,2^{\prime}-1.5144 ; 3,3^{\prime}-1.5153 ; 4,4^{\prime}-1.5120 ; 5,5^{\prime}-1.5163 \mathrm{eV} . \mathrm{T}=4.2 \mathrm{~K} . \lambda_{\text {excit }}=6328 \AA$. 


\section{PHOTOLUMINESCENCE SPECTRA OF NEW SEMI-INSULATING SPECIALLY UNDOPED GaAs MATERIALS}

In this section a new specially undoped semiinsulating GaAs material AGCP-5V obtained by the Czochralski method is investigated by the PL method using high resolution spectroscopy.

A typical PL spectrum of such samples at $4.2 \mathrm{~K}$ in the exciton region is shown in fig. 8 (curve 1 ).

This spectrum resembles the spectrum of perfect GaAs samples [17] obtained by the MBE method and differs from the spectra of AGCP-3 and AGCP-5 materials by the following: new materials have

- a higher quantum yield of PL;

- a richer structure of the edge PL band $(1.514 \mathrm{eV})$ which consists of five lines: $1.5163,1.5144,1.5133$, $1.5153,1.5120 \mathrm{eV}$ (the first three lines are sharp peaks, the last two are the bands); in these materials we observed

- presence of the two additional lines 1.5163, $1.5144 \mathrm{eV}$ in the region of the longitudinaltransverse splitting of excitons;

- the redistribution of intensities between lines 1.5133 and $1.5120 \mathrm{eV}$;

- absence of the line $1.5113 \mathrm{eV}$.

Decreasing of $I_{\text {excit }}$ leads to one structureless band with the maximum at $1.5137 \mathrm{eV}$ (fig. 8, curves 2-5) for $I_{\text {excit }}<0.08 \cdot I_{0}$.

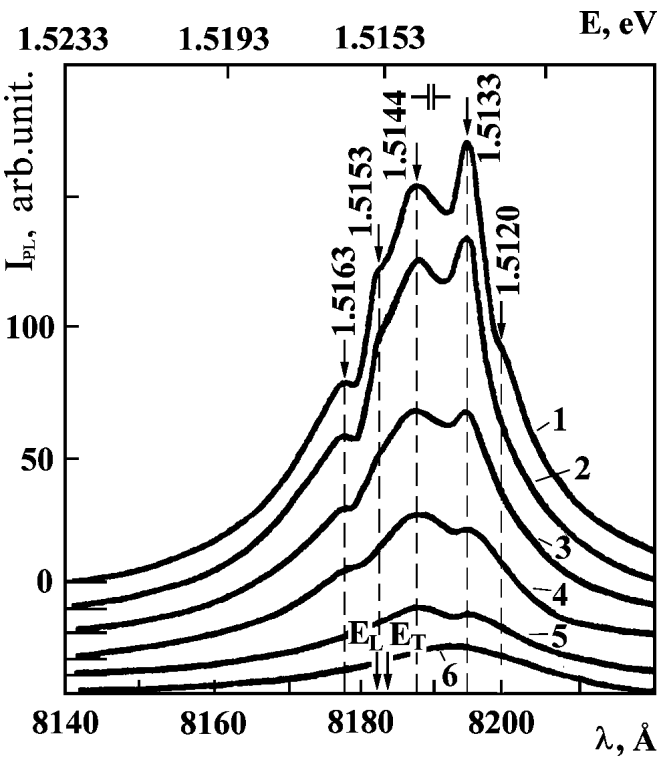

Fig. 10. PL spectra of AGCP-5V material at different temperatures: $1-4.2,2-6,3-10,4-17,5-26,6-$ $43 \mathrm{~K}: \lambda_{\text {excit }}=6328 \AA$.
Dependencies of PL intensity at the maxima of the considered lines and their energies on the laser excitation level are shown in fig. 9. The first dependence is described by the relation $I_{\mathrm{PL}} \approx\left(I_{\text {excit }}\right) \alpha^{i}$, were $\alpha^{i}=1.1$ and 2.0 at $0.29\left(I_{0}<I_{\text {excit }}<I_{0}\right.$ and $0.10 \cdot I_{0}<I_{\text {excit }}<0.29 \cdot I_{0}$ respectively. Every PL maximum at various values of $I_{\text {excit }}$ stay unchanged.

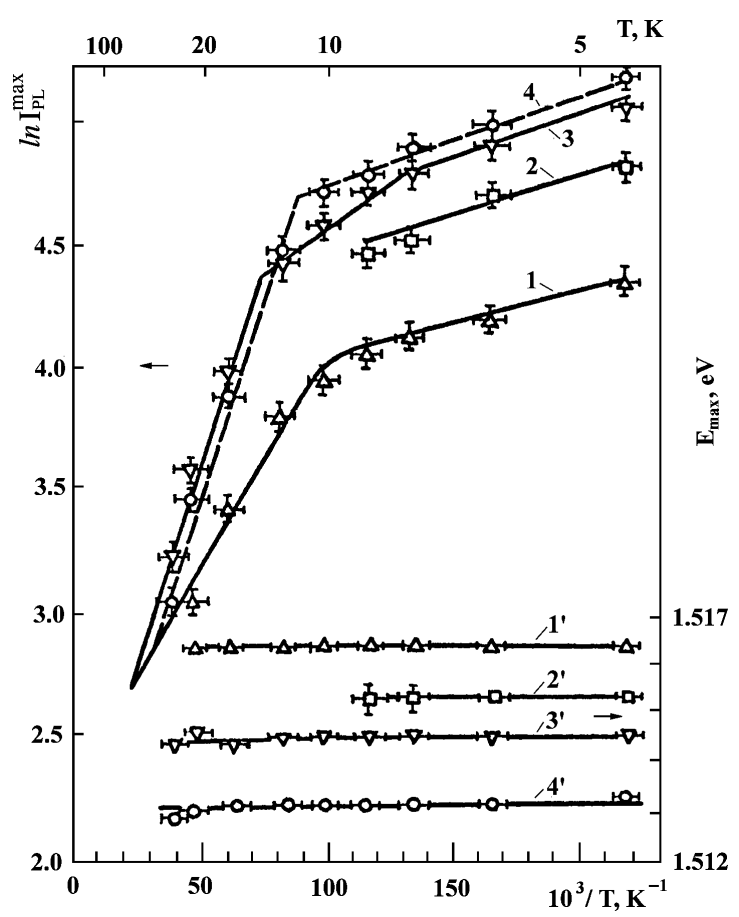

Fig. 11. Influence of temperature on intensity at maxima (1-4) and energies $\left(1^{\prime}-4^{\prime}\right)$ of PL lines of AGCP-5V material. $h \cdot \nu_{\max }: 1,1^{\prime}-1.5163 ; 2,2^{\prime}-1.5153 ; 3,3^{\prime}-1.5144 ; 4,4^{\prime}-$ $1.5133 \mathrm{~V} ; T=4.2 \mathrm{~K} . \lambda_{\text {excit }}=6328 \AA$.

The influence of temperature on PL spectra of this material is also remarkable(see spectra in fig. 10).

Indeed, it is sufficient to increase the temperature only by a few degrees as the lines 1.5153 and $1.5120 \mathrm{eV}$ overlap and they cannot be resolved. Decreasing of temperature leads to decreasing of the quantum yield of PL, increasing of the line half-width and modification of the line $1.5163 \mathrm{eV}$ (at $10 \mathrm{~K}$ ) (it has the form of a step, and at $20 \mathrm{~K}$ it disappears) (curve 1-4 in fig. 10). The lines 1.5144 and $1.5133 \mathrm{eV}$ which are yet present at $26 \mathrm{~K}$ with increasing of temperature spread out into a structureless band with the maximum at $1.5137 \mathrm{eV}$ (fig. 10, curve 5).

The changes of PL intensity at the maxima and the line energies as a function of temperature are presented in fig. 11.

Line $1.5144 \mathrm{eV}$ have two activation energies (1.1 and $5.0 \mathrm{meV}$ ), and lines 1.5163 and $1.5133 \mathrm{eV}$ have the activation energy 3.5 and $5.0 \mathrm{meV}$, respectively. These activation energies are dependent on the slope of lines $\ln \left(\frac{I_{0}}{I}-1\right)$ as a function of $10^{3} / T(\mathrm{~K})$ in the region of the most remarkable decreasing of the quantum yield of the recombination radiation. 
Let us analyse the data obtained. The nature of the lines 1.5133 and $1.5120 \mathrm{eV}$ was considered in the previous section. These lines are due to $\left(D^{0}, h\right)$ and $\left(\mathrm{C}_{\mathrm{As}}^{0}, X\right)$ complexes respectively, that is proved by their spectral position, the obtained values of $\alpha_{i}$, the thermal activation energies as well as the independence of the energy maxima on temperature and $I_{\text {excit }}$.

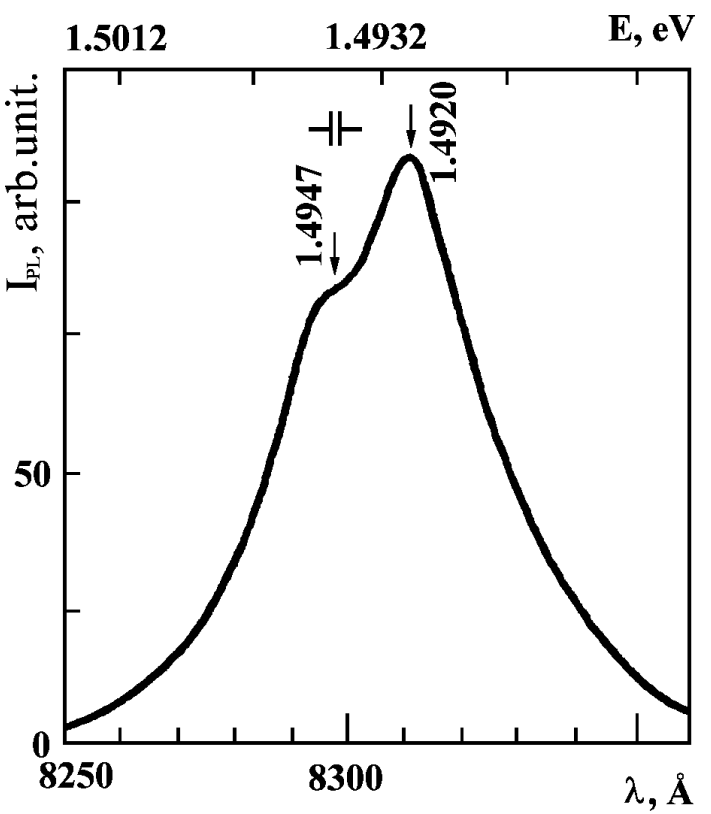

Fig. 12. Profile of the PL band $1.490 \mathrm{eV}$ in spectra of AGCP-5V material. $T=4.2 \mathrm{~K} ; \lambda_{\text {excit }}=6328 \AA$.

The line $1.5144 \mathrm{eV}$ has the lux-intensity characteristics similar to the lines 1.5133 and $1.5120 \mathrm{eV}$. Its spectral position is unchanged with increasing temperature and the excitation level and agrees with the calculated one for the exciton bound to the neutral donor $\left(D^{0}, X\right)$. The temperature dependence of the intensity of this band differs from that of $\left(D^{0}, h\right)$ in the range $7.6-13.3 \mathrm{~K}$. This allows to find the activation energy $\approx 1 \mathrm{meV}$ (fig. 11) and the thermal activation energy $5.0 \mathrm{meV}$. These values correspond to the theoretically predicted energy of the neutral donor ionisation energy $\left(D^{0} \rightarrow D^{+}+e\right)$ and the dissociation of the exciton bound to the neutral donor into a neutral donor and free exciton $\left(\left(D^{0}, X\right) \rightarrow D^{0}+X\right)$. These facts additionally indicate on correspondence of the line $1.5144 \mathrm{eV}$ to EIC $\left(D^{0}, X\right)$. This adds new data and agrees with data of other papers $[6,10,17,18]$, where ultra-purity GaAs doped with different impurities epitaxial layers were studied.

Two lines 1.5163 and $1.5153 \mathrm{eV}$ are not connected with EIC because they have not such a strong temperature dependence. The thermal activation energy of the first line is $3.5 \mathrm{meV}$ and it is close to the free exciton binding energy $\left(R_{y}=4.2 \mathrm{meV}[19]\right)$. These lines lie in the exciton resonance region $(n=1)\left(E_{n=1}=1.515 \mathrm{eV}\right)(4.2 \mathrm{~K})$ [19] and have doublet structure.
Usually the doublet structure in spectra of the resonance PL of GaAs is described in the framework of a polariton model according to which the shortwave component is due to the emission of light from the upper polariton branch and longwave one is due to the emission of light from the low polariton branch $[12,13,19]$.

The intrinsic excitation of a crystal is a polariton type when the exciton damping $\Gamma$ is less than the critical value of $\Gamma_{\text {cr }}[13]$

$$
\Gamma_{\mathrm{cr}}=2 \cdot E_{T}\left(\frac{2 \cdot \varepsilon_{0} \cdot \Delta_{\mathrm{LT}}}{M \cdot c^{2}}\right)^{\frac{1}{2}}
$$

where $E_{T}$ is the transverse exciton energy, $\Delta_{\mathrm{LT}}$ is longitudinal-transverse splitting of excitons, $\varepsilon_{0}$ is the background dielectric constant, $M=\left(m_{e}+m_{h}\right)$. Taking $\varepsilon_{0}=12.6$, the energy of the longitudinal exciton $E_{L}=1.51515 \mathrm{eV}$ [20], $\Delta_{\mathrm{LT}}=0.10-0.13 \mathrm{meV}[12,13,19]$, $M=0.6 \cdot m_{0}[12]$ we obtain $\Gamma_{c r}=0.27-0.31 \mathrm{meV}$. To estimate $\Gamma$ with a plausible error in a polariton model for the AGCP-5V material from experiment is difficult because of very weak intensity of the line $1.5153 \mathrm{eV}$. So it is desirable to use the results of [20] on the properties of the GaAs layers irradiated by gamma quanta. Under irradiation the polariton PL spectra are changed considerably. The components 1.5151 and $1.5153 \mathrm{eV}$ are shifted to the energies 1.5148 and $1.5157 \mathrm{eV}$ and the low-energy component is broaden. These changes are due to:

- decreasing of the non-radiative lifetime and diffusion length of excitons;

- increasing of the elastic scattering probability of excitons, and are the natural sequences of creating of new non-radiative recombination and scattering centres.

Moreover, even in the $\gamma$-irradiated samples the value of the total damping $\Gamma$ calculated in the exciton resonance region $(n=1)$ is less than $\Gamma_{c r}$. Because the distance of components of the polariton doublet in irradiated samples is $0.9 \mathrm{meV}$ and in AGCP-5V material is $1.0 \mathrm{meV}$ it can be accounted that the lines $1.5163 \mathrm{eV}$ and $1.5153 \mathrm{eV}$ are also due to the polariton emission from upper and low polariton branches respectively. This indicates that in AGCP-5V samples the concentration of scattering and recombination centres is considerable and essentially greater than that in the ultra-purity GaAs layers. But in the AGCP-5V this concentration is smaller than in AGCP-3, AGCP-4, AGCP-5 and GaAs(Cr) materials let alone the semi-insulating AR and AGP materials as the polariton PL in these materials was not observed.

The validity of the conclusion on the nature of the lines 1.5163 and $1.5153 \mathrm{eV}$ is proved by the observation of the lines 1.5153 and $1.5120 \mathrm{eV}$ as the bands, the broadening of all lines in comparison with the PL is lines of ultra-purity GaAs layers, the presence of the polariton emission from the upper polariton branch at all levels of the laser excitation and temperatures. These add new results to the data of works [21-23] in which the polariton 
emission from upper and low polariton branches was registered in initial and intercalated $2 \mathrm{H}-\mathrm{PbI}_{2}$ layered single crystals. The results correlate also with the theory [24] developed for crystals with considerable concentration of scattering centres.

To conclude, let us consider the background impurities and other defects in AGCP-5V materials. These materials differ from other GaAs materials by considerable contents of shallow donors which give the lines 1.5144 and $1.5133 \mathrm{eV}$ (this is proved by domination of the recombination radiation through $\left(D^{0}, X\right)$ (line $\left.1.5144 \mathrm{eV}\right)$ and $\left(D^{0}, h\right)$ (line $\left.1.5133 \mathrm{eV}\right)$ complexes over recombination radiation through $\left(\mathrm{C}_{\mathrm{As}}^{0}, X\right)$ channel).

For the saving of semi-insulating properties of AGCP$5 \mathrm{~V}$ material one should expect the creation of new acceptors beside with the known shallow $\mathrm{C}_{\mathrm{As}}^{0}$ acceptor centres. Their arising is proved by appearance of a new intense band $1.4947 \mathrm{eV}$ (fig. 12).

The last band is similar to the wide band $1.495 \mathrm{eV}$ registered by us formerly in PL spectra of low-doped GaAs crystals $\left(n=1.5 \cdot 10^{16} \mathrm{~cm}^{-3}\right)$. This band is due to an electronic transition $E_{c}-A$. However the main channel of the recombination radiation in this spectrum region is the channel $\left(E_{c}-\mathrm{C}_{\mathrm{As}}^{0}\right.$ ) (the band $1.492 \mathrm{eV}$ ). Moreover, the point defect concentration in $\mathrm{AGCP}-5 \mathrm{~V}$ is so small that $(d, X)$ excitons (lines in the region $1.511-1.505 \mathrm{eV}$ ) was not observed even at maximum sensitivity of the equipment used.

Hence, the new commercial specially undoped semiinsulating GaAs material AGCP- $5 \mathrm{~V}$ is one of the best available.

\section{CONCLUSION}

1. Traditional high temperature annealing of semiinsulating GaAs substrates aggravates their structure perfection. This is due to the dissociation of GaAs, the depletion of the near surface layer by arsenic atoms, the diffusion of carbon, copper and other elements both from environment and perhaps from the bulk into the near surface region.

2. The fine structure of the exciton and impurity PL bands is due to:
- polaritons of upper and low polariton branches;

- $\left(D^{0}, h\right),\left(D^{0}, X\right),\left(\mathrm{C}_{\mathrm{As}}^{0}, X\right),(d, X)$ complexes;

- electronic transitions between the conduction band and the shallow neutral carbon acceptor $\left(E_{c}-\mathrm{C}_{\mathrm{As}}^{0}\right)$;

- donor-acceptor pairs in which an acceptor is $\mathrm{C}_{\mathrm{As}}^{0}$ and perhaps $\mathrm{Zn}_{\mathrm{As}}^{0}$ in the $1 S_{3 / 2}$ ground state with thermal ionisation energies 26.5 and $30.2 \mathrm{meV}$ respectively.

3. Change of recombination radiation channels at increasing intensity of excited light from $(d, X)$ complexes and $D-A$ pairs, in which $\mathrm{Zn}_{\mathrm{As}}^{0}$ may be an acceptor, to $\left(D^{0}, h\right)$ complexes and $D-A$ pairs in which $\mathrm{C}_{\mathrm{As}}^{0}$ is an acceptor, was found and studied.

4. The lux-intensity dependencies of polariton emission from upper polariton branch and of the $\left(D^{0}, h\right)$, $\left(\mathrm{C}_{\mathrm{As}}^{0}, X\right),(d, X)$ complexes are well described by the theory in [15] developed for steady state concentration of free excitons and charge carriers.

5 . One of the main background impurities in semiinsulating GaAs substrates from the AR-19, AR-40, AGP-2, AGP-3, AGP-4, AGP-5, AGCP-3, AGCP-4, AGCP-5, AGCP-5V and $\mathrm{GaAs}(\mathrm{Cr})$ materials is carbon.

6 . The commercial specially undoped semi-insulating GaAs material AGCP-5V is one of the best available materials. Its characteristic are:

- presence of the polariton emission;

- considerable content of shallow donors and new acceptors (the band $1.495 \mathrm{eV}$ );

- extremely low contents of point-structure defects.

\section{ACKNOWLEDGMENTS}

The authors are thankful to Prof. M. P. Lisitsa for the discussion and Dr. V. V. Teslenko for the measurements of the ESR GaAs spectra.
[1] L. G. Gassanov, E. P. Laurs, M. P. Lisitsa, F. V. Motsnyi, Preprint No. 11 of the Institute of Physics NASU. Kyiv (1987).

[2] K. D. Glinchuk, A. V. Prokhorovich, V. I. Vovnenko, Phys. Status Solidi A 34, 777 (1976).

[3] Y. Fudjivara, T. Nishino, Y. Hanakawa, Jpn. J. Appl. Phys. 21, 727 (1982).

[4] W. H. Koshel, R. S. Smith, P. Hiesinger, J. Electrochem. Soc. 128, 1331 (1981).

[5] O. Masashi, K. Nakai, K. Dazai et al., Jpn. J. Appl. Phys. 13, 1121 (1974).
[6] D. J. Ashen, P. J. Dean, D. T. Hurle et al., J. Phys. Chem. Solids 36, 1041 (1975).

[7] N. S. Averkiev, T. K. Ashirov, A. A. Gudkin, Fiz. Tech. Poluprovodn. 15, 1970 (1981).

[8] N. S. Averkiev, T. K. Ashirov, A. A. Gudkin, Fiz. Tech. Poluprovodn. 17, 97 (1983).

[9] N. Noto, Y. Kitagawara, T. Takahashi, T. Takenaka, Jpn. J. Appl. Phys. 25, L394 (1986).

[10] R. R. Sharma, S. Rodriguez, Phys. Rev. 153, 823 (1967).

[11] J. I. Pankov, Optical Processes in semiconductors (Prentice-Hall, Inc. New Jersey, 1971) [Translated into 
Russian (Mir, Moscow, 1973)].

[12] F. Askary, F. Y. Yu, Solid State Commun. 47, 241 (1983).

[13] Yu. V. Jilyaev, V. V. Rossin, T. V. Rossina, V. V. Travnikov, Fiz. Tverd. Tela (Leningrad) 28, 2688 (1986).

[14] E. H. Bogardus, H. B. Bebb, Phys. Rev. 176, 993 (1968).

[15] M. S. Brodin, A. O. Gushcha, V. N. Khotiaintsev et al., Phys. Status Solidi B, 144, 863 (1987).

[16] M. K. Sheinkman, I. B. Ermolovich, G. L. Belenkii, Fiz. Tverd. Tela (Leningrad) 10, 2628 (1968).

[17] Moliekuliarno-luchievaia epitaksiia $i$ getierostruktury (Molecular Beam Epitaxy and Heterostructures), edited by L. L. Chang, K. Ploog (Mir, Moskow, 1989).

[18] M. Ozeki, K. Nakai, K. Dazai, O., J. Appl. Phys. 13,
1121 (1974).

[19] D. D. Sell, S. E. Stokowski, R. Dingle, J. V. Di Lorenzo, Phys. Rev. 7, 4568 (1973).

[20] Yu. V. Jilyaev, V. V. Rossin, T. V. Rossina, V. V. Travnikov, Fiz. Tech. Poluprovodn. 22, 1885 (1988).

[21] M. P. Lisitsa, F. V. Motsnyi, A. M. Yaremko, A. P. Litvinchuk, Fiz. Tverd. Tela (Leningrad) 27, 1008 (1985).

[22] M. P. Lisitsa, F. V. Motsnyi, A. M. Yaremko, Ukr. Fiz. Zh. 32, 1185 (1987).

[23] M. P. Lisitsa, A. V. Melejyk, F. V. Motsnyi, Ukr. Fiz. Zh. 37, 827 (1992).

[24] V. I. Sugakov, Opt. Spectroskop. 26, 732 (1969).

\title{
ВИВЧЕННЯ ПРИРОДИ ЦЕНТРІВ І МЕХАНІЗМІВ ВИПРОМІНЮВАЛЬНОӦ РЕКОМБІНАЦІЇ В НАПІВІЗОЛЮЮЧИХ КРИСТАЛ АХ GaAs
}

\author{
В. Г. Комаров ${ }^{(1)}, \Phi$. В. Моцний ${ }^{(1)}$, В. Ф. Моцний ${ }^{(1)}$, О. С. Зінець ${ }^{(2)}$ \\ (1) Iнститут фізики напівпровідників НАН Украйни, \\ пр. Науки 45, Київ, 252028, Украӥна \\ men./факс: +380 (044) 265-82-04, e-mail: motsnyi@sun.semicond.kiev.ua. \\ (2) Інститут ядерних досліджень НАН Украӥни, \\ пр. Науки 47, Київ, 252028, Украӥна \\ e-mail:zinets@kinr.kiev.ua.
}

\begin{abstract}
У роботі досліджено низькотемпературні спектри фотолюмінесценції напівізолюючих кристалів GaAs, отриманих за методом Чохральського при різних технологічних умовах. Однією з основних фонових домішок у таких матеріялах є вуглець. Традиційний високотемпературний відпал напівізолюючих пластин GaAs cу ттєво погіршує іхню структурну досконалість, оскільки в приповерхневій області виникає прові дний шар товшиною кілька мкм. Виявлено тонку структуру краєвої (1.514 еВ) та домішкової (1.490 еВ) смуг. Установлено, що ця структура зумовлена: а) випромінюванням поляритонів із верхньої та нижньої поляритонних гілок; б) випромінювальною рекомбінацією вільних дірок на мілких нейтральних донорах $\left(D^{0}\right.$, $h)$; в) випромінювальною рекомбінацією екситонів, зв'язаних на нейтральних донорах $\left(D^{0}, X\right)$, на мілких акцепторах вуглецю $(C, X)$ та на точкових структурних дефектах $(d, X) ;$ г) електронними переходами між зоною провідности та мілким нейтральним акцептором вуглецю; д) електронними переходами між донорно-акцепторними парами, у яких вуглець i, можливо, цинк є акцепторами в основному $1 S_{3 / 2}$ стані. Експериментальні люкс-інтенсивностні зале жності випромінювання поляритонів із верхньої поляритонної гілки та фотолюмінесценції $\left(D^{0}, h\right),(\mathrm{C}, X),(d, X)$-комплексів задовільно узгоджуються з теоретичними. Показано, що одним із найліпших напівізолюючих матеріялів GaAs 6 на сьогодні новий промисловий вітчизняний матеріял АГЧП-5В, який відрізняється від відомих значним умістом мілких донорів, появою нових акцепторів поряд із відомими мілкими акцепторами вуглецю.
\end{abstract}

